\title{
Pemberdayaan Masyarakat di Kawasan Menoreh Desa Pagerharjo dan Sekitarnya dalam Penggunaan Smartphone Berbasis Android
}

\author{
Rella Mareta ${ }^{*}$, Fitri Puspa Sari ${ }^{2}$ \\ ${ }^{1,2}$ Departemen Teknik Elektro dan Informatika, Sekolah Vokasi, Universitas Gadjah Mada \\ *Email: rella.mareta@ugm.ac.id
}

\begin{abstract}
Abstrak
Kabupaten Kulon Progo merupakan salah satu Kabupaten di D.I. Yogyakarta yang memiliki potensi yang besar, terutama potensi pariwisatanya. Desa Pagerharjo yang terletak di Kecamatan Samigaluh, yang merupakan bagian dari kawasan Menoreh, merupakan daerah yang sedang dikembangkan potensi wisata maupun produk lokalnya. Namun potensi yang besar ini belum begitu diketahui secara luas oleh masyarakat. Kemajuan teknologi seperti smartphone berbasis android sudah banyak dikenal sebagai salah satu media online yang populer digunakan untuk promosi.Meskipun demikian, pemanfaatan smartphone berbasis android ini sebagai media promosi potensi daerah belum begitu maksimal, terutama di desa Pagerharjo dan sekitarnya. Oleh karena itu, Departemen Teknik Elektro dan Informatika Sekolah Vokasi Universitas Gadjah Mada melakukan kegiatan Pelatihan Penggunaan Smartphone berbasis Android. Pelatihan ini dilakukan dengan peserta dari kalangan Karang Taruna dan Ibu PKK dari Desa Pagerharjo dan sekitarnya
\end{abstract}

Kata Kunci: Smartphone Android, Pagerharjo, wisata

\begin{abstract}
Kulon Progo Regency is one of the districts in Yogyakarta Special Region which has great potential, especially its tourism potential. Pagerharjo village located in District Samigaluh, which is part of the Menoreh region, is an area that has a lot of tourism potential and local products. But this great potential has not been widely known by the public. Advances in technology such as android-based smartphones are widely known as one of the popular online media used for promotion. However, the utilization of this android-based smartphone as a medium of potential promotion of the region has not been so maximized, especially in the Pagerharjo and its surrounding areas. Therefore, the Department of Electrical and Informatics Engineering, Vocational School of Gadjah Mada University conducted the Training of Android Smartphone. The training was conducted with participants from Pagerharjo Village's Youth and Housewife Organization.
\end{abstract}

Keywords: Android smartphone, Pagerharjo, tourism

\section{PENDAHULUAN}

Kabupaten Kulon Progo memiliki potensi wisata alam yang besar. Destinasi wisata di Kulon Progo di dominasi wisata alam baik pantai, perbukitan, air terjun, kebun teh, dan lain-lain. Beberapa objek wisata terkenal di Kabupaten Kulon Progo adalah Waduk Sermo dan Kalibiru. Waduk sermo adalah sebuat bendungan dimana para wisatawan dapat melihat pemandangan indah dan berkeliling di waduk dengan menyewa perahu yang disediakan oleh pengelola. Sedangkan Kalibiru menawarkan pemandangan Waduk Sermo dari atas bukit. Pengelola juga menyediakan spot foto yang unik sebagai daya tarik bagi wisatawan. 
Perkembangan dua destinasi wisata tersebut mendorong pemerintah daerah Kulon Progo dan kelompok sadar wisata beramai-ramai mengembangkan destinasi wisata baru yang diharapkan dapat menyejahterahkan masyarakat sekitar.

Destinasi wisata baru yang sedang berkembang adalah Air Terjun Kedung Pedut yang menarik para wisatawan dengan airnya yang jernih. Pengembangan kawasan wisata di daerah Kulon Progo ini selaras dengan program Dinas Pariwisata Pusat yang sedang mengembangkan Kawasan Strategis Pariwisata Nasional (KSPN) Borobudur yang meliputi sebagian Kulon Progo dan Magelang. Hal ini menjadi salah satu motivasi pemerintah daerah untuk mengembangkan daerah wisata di Kulon Progo.

Salah satu daerah yang termasuk KSPN Borobudur adalah kecamatan Samigaluh yang berada di kawasan perbukitan Menoreh. Daerah ini dipilih karena pada nantinya wisatawan Borobudur tidak boleh mendekat dan memegang batubatu candi Borobudur sehingga hanya bisa melihat dari jauh. Oleh karena itu, kawasan menoreh sangat potensial untuk dijadikan destinasi wisata karena dari kawasan ini wisatawan dapat melihat Borobudur dari jauh.

Kecamatan di Kabupaten Kulon Progo yang memiliki potensi wisata yang besar adalah kecamatan Samigaluh. Salah satu potensi wisata kecamatan tersebut adalah kebun teh Dlingo dan Tritis yang terletak di desa Pagerharjo dan Ngargosari. Kebun teh ini menawarkan pemandangan yang indah dan udara yang sejuk. Meskipun daerah ini memiliki potensi wisata yang besar tetapi jarang ada orang yang tahu.

Untuk menyebarkan informasi dan sebagai sarana promosi daerah wisata dan produk unggulan di kawasan menoreh ini diperlukan keaktifan dan kemampuan warga dalam ikut serta mempromosikan potensi dari wilayah mereka tersebut. Salah satu media yang banyak digunakan dan mudah diperoleh saat ini ialah smartphone berbasis android. Dengan kemampuan dan pengetahuan yang cukup, warga dapat memanfaatkan smartphone berbasis android ini untuk mempromosikan potensi wilayah mereka melalui jejaring sosial.

Dilatarbelakangi oleh hal-hal yang telah disebutkan tersebut, pengabdian masyarakat ini direncanakan untuk dilaksanakan di desa Pagerharjo yang merupakan salah satu desa yang menjadi bagian dari KSPN Borobudur, untuk mensosialisasikan penggunaan smartphone Android sehingga promosi dan informasi wisata yang terdapat di desa tersebut dapat tersebar ke masyarakat luas di Indonesia dan pada akhirnya akan dapat meningkatkan tingkat kesejahteraan warga desa Pagerharjo.

\section{METODE}

Permasalahan yang dihadapi oleh desa yang berada kawasan menoreh in adalah kebutuhan peningkatan skill dan wawasan masyarakat tentang cara pemanfaatan smartphone berbasis android sebagai sarana promosi wisata, jual beli online, dan termasuk promosi produk unggulan lokal kawasan tersebut.

Banyak tempat-tempat wisata dan produk lokal yang potensial di daerah tersebut yang belum terekspos ke para wisatawan karena mereka belum mendapatkan informasi dan promosi pada media online yang dapat diakses oleh khalayak ramai.

Solusi yang ditawarkan dalam mengatasi masalah tersebut adalah berupa pelatihan penggunaan smartphone berbasis android dalam rangka promosi potensi wilayah tersebut. Pelatihan ini dilakukan dengan tujuan agar setelah program pengabdian selesai, masyarakat dapat memanfaatkan smartphone berbasis android yang dimiliki secara maksimal untuk promosi potensi wisata dan produk unggulan maupun jual beli secara online. Sasaran dari pengabdian ini adalah karang taruna dan ibu PKK di daerah Pagerharjo dan sekitarnya.

Kegiatan ini direncanakan memiliki target luaran antara lain meningkatnya kemampuan warga dalam penggunaan smartphone berbasis android dalam 
menggunakan beberapa aplikasi media sosial untuk sarana promosi potensi wilayah ataupun jual beli online.

Indikator keberhasilan capaian kegiatan ini adalah:

1. Terlaksananya pelatihan meliputi cara penggunaan dua aplikasi media sosial, serta cara melakukan pencarian atau menggunakan webite yang sudah tersedia.

2. Peserta mampu menginstall aplikasi, membuat akun baru, mengunggah foto dan memberi keterangan foto.

3. Peserta mampu menambah pengikut dan komunikasi dengan akun lain.

\section{HASIL DAN PEMBAHASAN}

Berdasarkan solusi yang ditawarkan pada bagian pendahuluan, telah dilaksanakan rangkaian kegiatan pengabdian masyarakat yang berlangsung dari bulan Maret 2017 sampai Oktober 2017. Kegiatan ini merupakan bagian dari rangkaian kegiatan pengabdian masyarakat oleh Departemen TEDI Sekolah Vokasi UGM. Kegiatan-kegiatan yang telah dilaksanakan adalah:

1. Survey ke daerah tujuan untuk mendapatkan data yang akurat mengenai keadaan yang ada disana dan masalah yang dihadapi. Setelah melakukan survey dan koordinasi dengan pengurus setempat, dan dengan mempertimbangkan berbagai faktor seperti ketersediaan dana dan

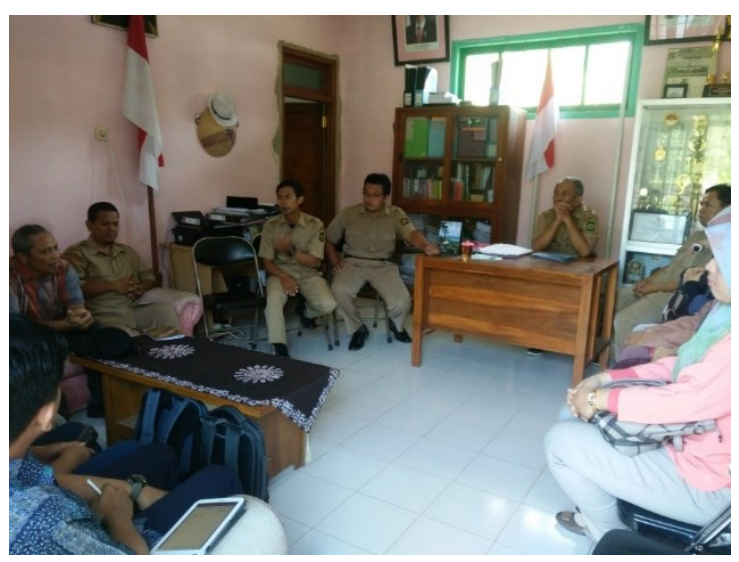

Gambar 1. Koordinasi dengan pengurus Desa Pagerharjo kemudahan akses lokasi, maka Desa Pagerharjo, Kecamatan Samigaluh, Kawasan Menoreh dipilih sebagai tempat pelaksanaan kegiatan pengabdian masyarakat tahun 2017.

2. Koordinasi dengan Bappeda, Pengurus Desa Pagerharjo, dan Pengurus Kecamatan Samigaluh untuk menyepakati rencana kegiatan dan waktu pelaksanaan. Kemudian dari proses survey dan koordinasi ini ditentukan solusi berupa pelatihan penggunaan aplikasi media sosial pada smartphone berbasis android untuk sarana promosi potensi daerah.

3. Persiapan kegiatan meliputi pemetaan kebutuhan, pembuatan materi pelatihan, penentuan jadwal dan lokasi pelatihan, koordinasi terkait sosialisasi kepada peserta pelatihan, persiapan alat dan sarana pendukung pendukung lainnya yang dibutuhkan untuk pelaksanaan kegiatan. Kegiatan ini dilakukan selama kurang lebih 2 bulan.

4. Pelaksanaan pelatihan aplikasi pada smartphone berbasis android dengan peserta sebanyak 30 orang dari Ibu PKK dan Karang taruna Desa Pagerharjo. Pelatihan cara penggunaan aplikasi media sosial pada smartphone berbasis android ini dilakukan di Balai Desa Pagerharjo dengan pertimbangan lokasi terdekat yang mudah dijangkau peserta dan ketersediaan sarana danprasarana yang dibutuhkan untuk kegiatan pelatihan ini. Aplikasi yang dipilih sebagai materi pelatihan ini

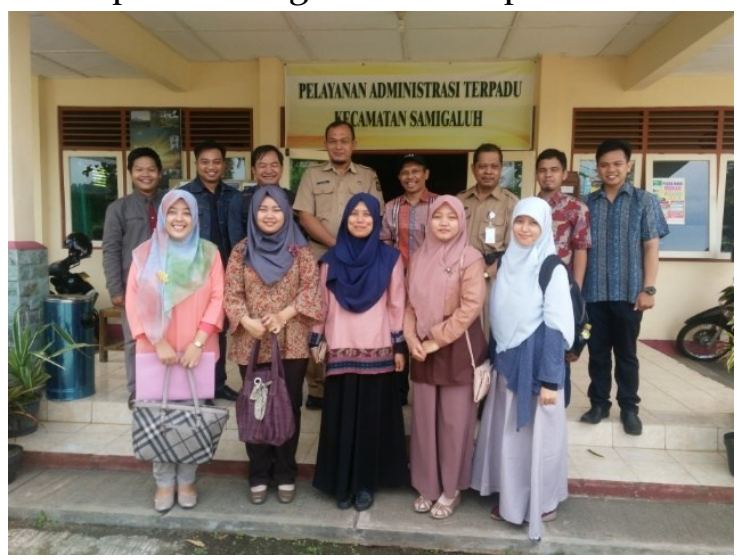

Gambar 2. Koordinasi dengan pengurus kecamatan Samigaluh 
adalah aplikasi Instagram dan aplikasi Line dikarenakan kedua aplikasi ini sangat populer sebagai media promosi secara online dan media komunikasi dalam jual beli online.

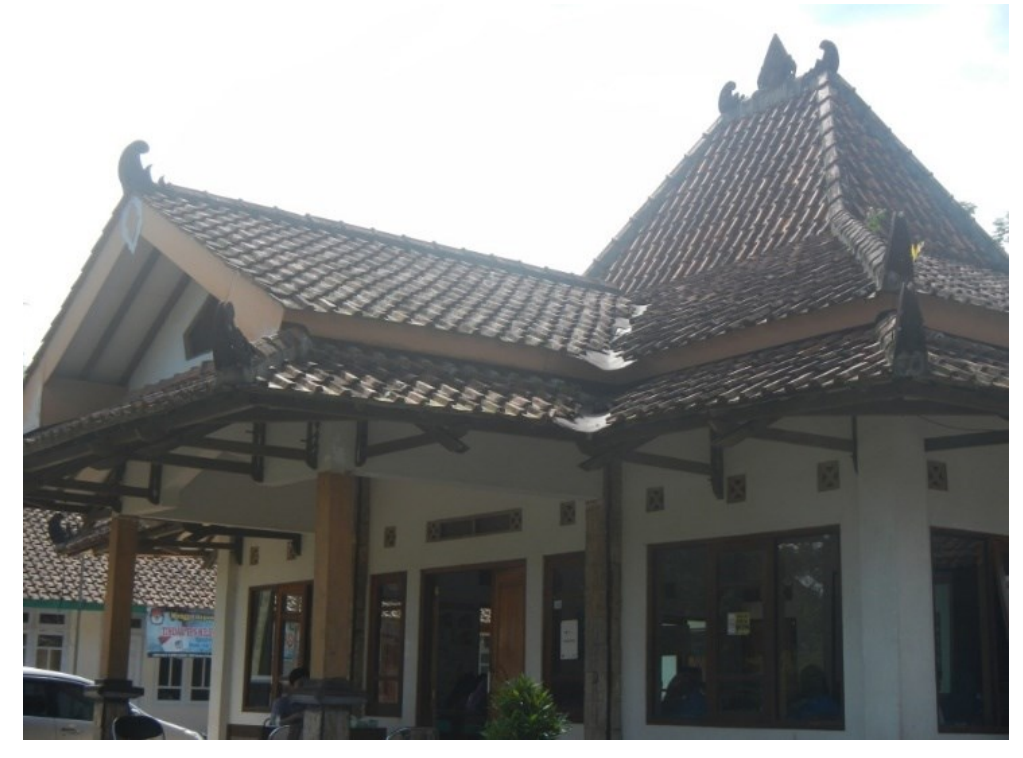

Gambar 3. Balai Desa Pagerharjo sebagai lokasi pelatihan

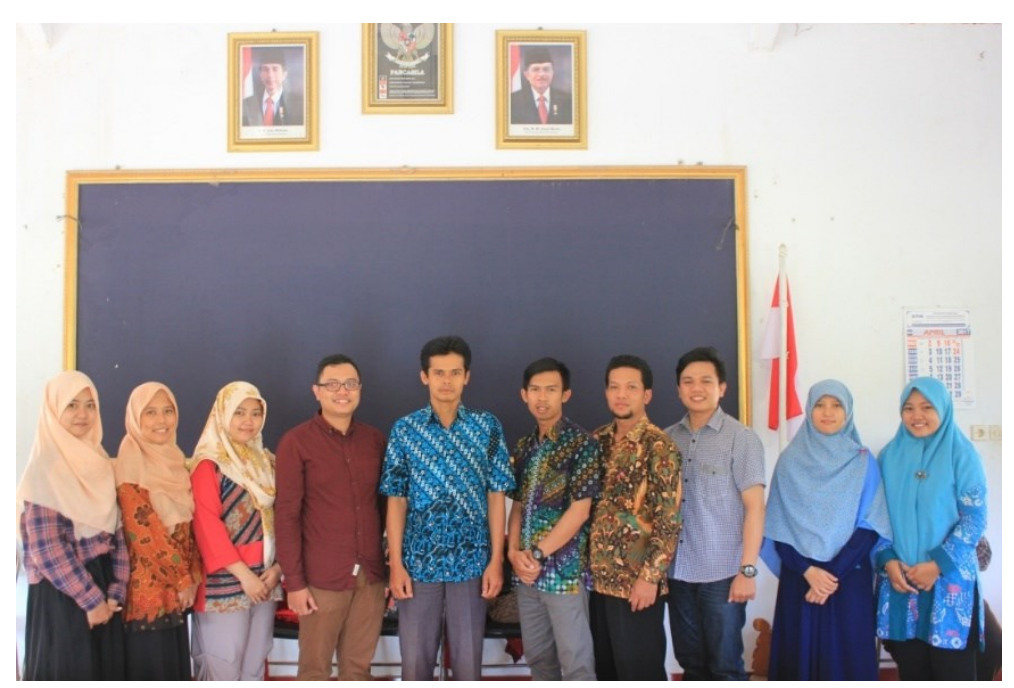

Gambar 4. Tim pengabdian dan pengurus Desa Pagerharjo

Cara penyampaian materi adalah dengan penyampaian materi oleh seorang instruktur yang berada di depan, dilengkapi dengan visualisasi dari laptop, layar dan projector. Kemudian peserta langsung mempraktikkan materi tersebut dengan smartphone atau tablet android yang ada, dengan bantuan arahan dari seorang asisten yang keliling kelas dan modul materi pelatihan yang sudah dibagikan ke masingmasing peserta.

Materi yang diberikan meliputi pelatihan Aplikasi Instagram dengan penjelasan tentang cara instalasi aplikasi instagram, cara membuat akun instagram, cara mengunggah foto, cara mengikuti akun lain, dan cara memprivat akun. Sedangkan pelatihan Aplikasi Line meliputi cara instalasi aplikasi line, cara registrasi ID line, 


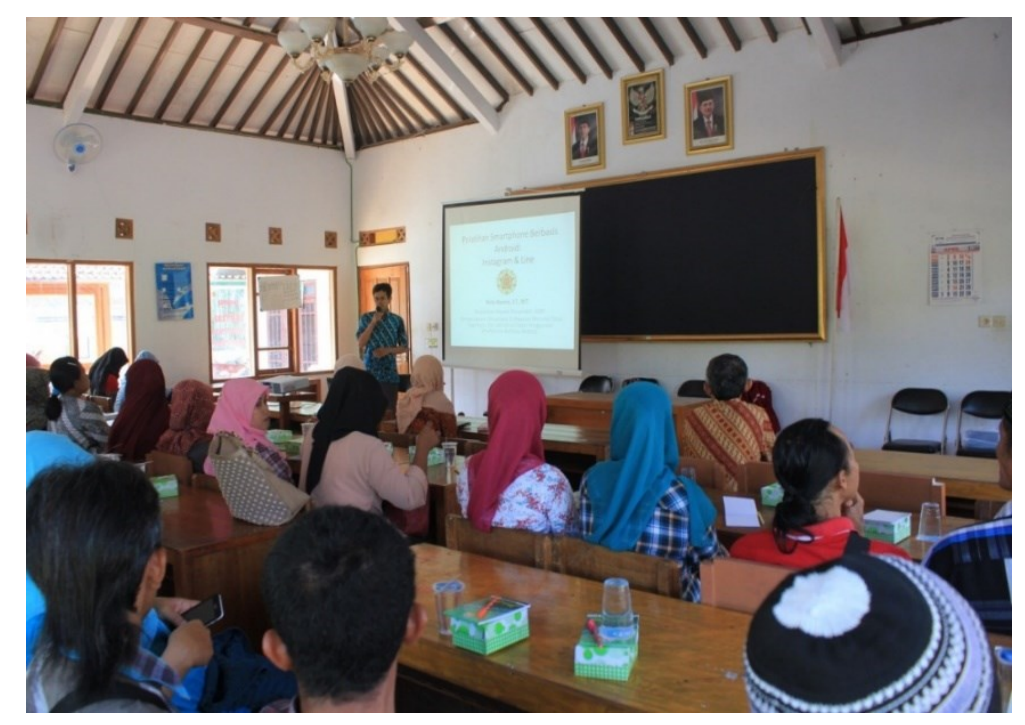

Gambar 4. Sambutan Kepala Desa Pagerharjo sebelum pelatihan dimulai

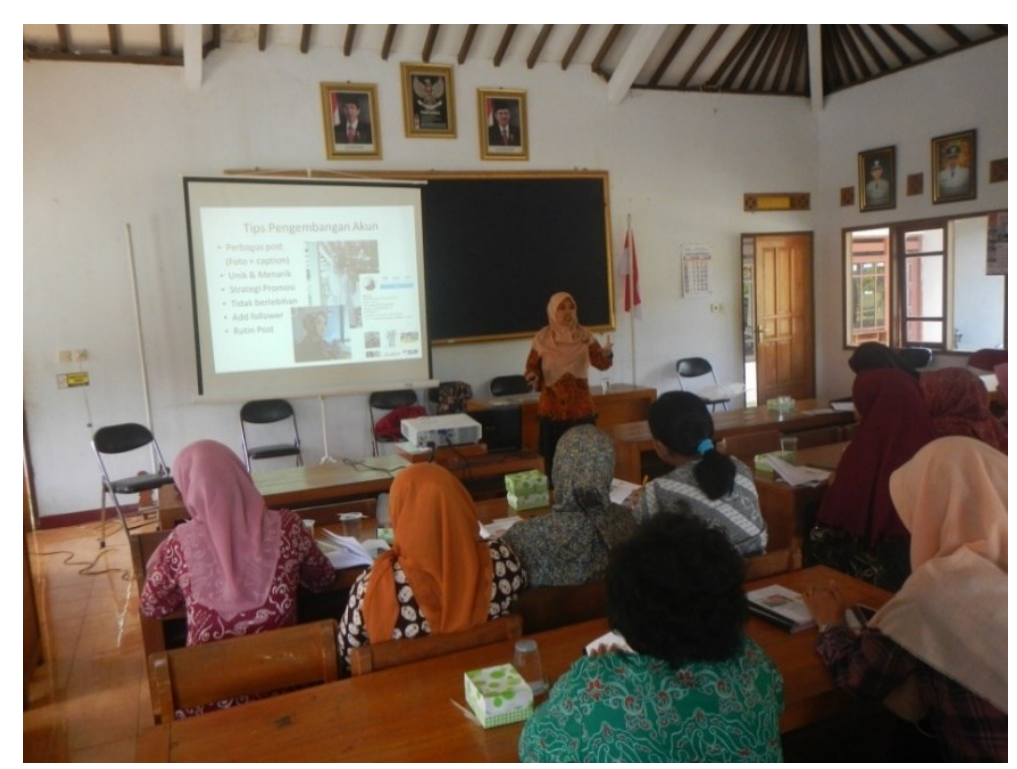

Gambar 5. Pelaksanaan Kegiatan Pelatihan

cara menambah teman di line, cara melakukan chat di line, cara mengirim gambar lewat chat, cara forward/meneruskan pesan ke akun lain, cara memasukkan teman lain ke dalam chat, cara membuat post di timeline, cara melakukan pengaturan privasi (khusus modul), caramematikan mode penambahan teman otomatis (khusus modul), cara memblokir user line (khusus modul).

Kegiatan pelatihan smartphone berbasis Android bagi masyarakat desa Pagerharjo dan sekitarnya, telah dilaksanakan pada hari Sabtu, 6 Mei 2017, bertempat di Balai Desa Pagerharjo. Pelatihan dilaksanakan sebanyak 2 sesi. Sesi 1 pada pukul 09:30 hingga pukul 10:40, sedangkan sesi 2 dilaksanakan pada pukul 10:50 hingga 11:50.

Pelatihan diberikan oleh Rella Mareta, staf pengajar dan peneliti dari Program Studi Elektronika dan Instrumentasi, Sekolah Vokasi, Universitas Gadjah Mada dengan dibantu oleh asisten, Rany Ayu, mahasiswi pada program yang sama. Sebanyak 30 warga desa Pagerharjo antusias mengikuti pelatihan smartphone berbasis Android sebagai media promosi. 


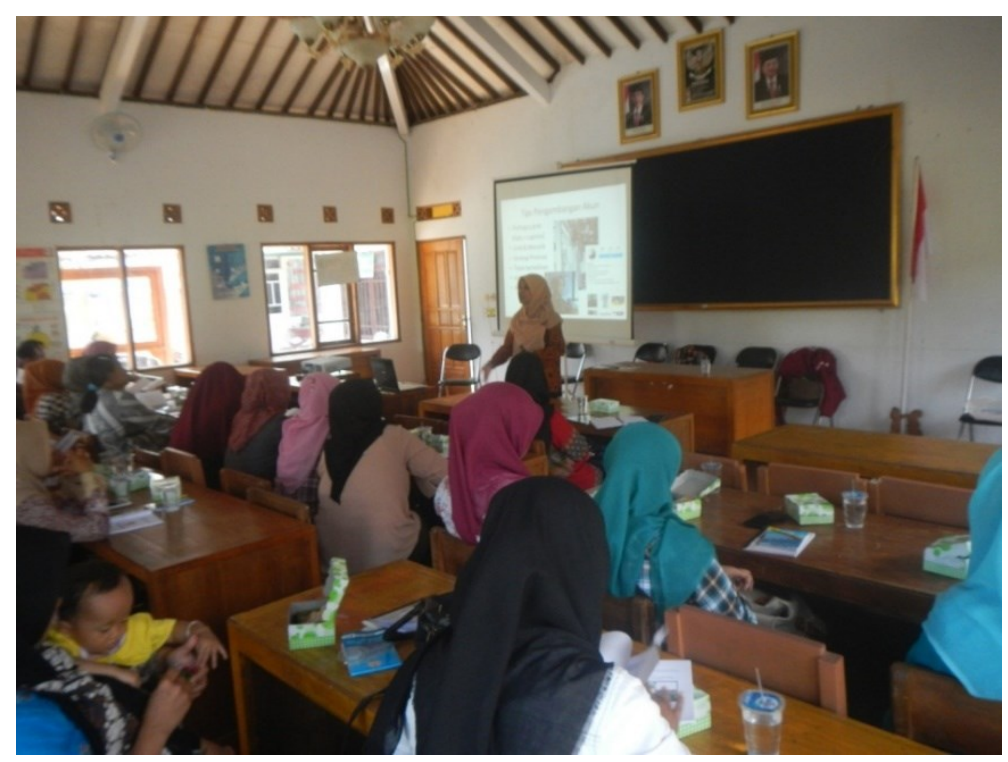

Gambar 6. Peserta mempraktikkan materi pelatihan

5. Pembuatan laporan, banner, poster, dan jurnal pengabdian masyarakat kurang lebih selama 1 bulan.

\section{SIMPULAN}

Kegiatan pemberdayaan masyarakat berupa pelatihan smartphone berbasis android di Desa Pagerharjo dan sekitarnya telah dilakukan dengan baik pada tanggal 6 Mei 2017. Berdasarkan evaluasi dari pelaksanaan kegiatan, terdapat sebuah kendala teknis yaitu keterbatasan internet yang memadai sehingga praktik langsung yang dilakukan peserta pada saat pelatihan kurang maksimal.

\section{DAFTAR PUSTAKA}

Pemerintah Kabupaten Kulon Progo. (2012). Rencana Tata Ruang Wilayah Kabupaten Kulon Progo 2012-2032. Wates: Sekretaris Daerah Kabupaten Kulon Progo

Pemereintah Provinsi Daerah Istimewa Yogyakarta (2010). Rencana Tata Ruang Wilayah Daerah Istimewa Yogyakarta 2009-2029. Yogyakarta: Sekretaris Daerah Profinsi Daerah Istimewa Yogyakarta

Dadang Rizki Ratman, SH.MPA. (2016). Pembangunan Destinasi Pariwisata
Prioritas 2016-2019. Jakarta: Deputi Bidang Pengembangan Destinasi dan Investasi Pariwisata Kementerian Pariwisata.

Tribunnews. (2016). Menpar Tinjau Kebun Teh Penyangga KSPN Borobudur. Yogyakarta 